\title{
MAPPING THE URBAN STRUCTURES OF THE MEGACITY ISTANBUL BY MEANS OF HIGH- RESOLUTION SATELLITE IMAGES
}

\author{
DOI: https://doi.org/10.18509/AGB.2021.10
}

UDC: 528.45:[528.837:629.783(560.118)

\section{Wolfgang Sulzer, Lena Mitterhuber, Sarah Kostka}

University of Graz, Institute for Geography and Regional Sciences, Graz, Heinrichstrasse 36, Austria

corresponding author: wolfgang.sulzer@uni-graz.at

\begin{abstract}
According to the UN, more than half of the world population is already living in urban areas, around 6,8\% thereof in socalled megacities, whose spatial dynamic is often difficult to keep track of, due to the high concentration of people who live in a relatively small area. The amount of people living in cities in general and in megacities in particular is going to increase further until 2030, which is why the study of megacities is getting more and more relevant as an object of research for Geography and remote sensing. The paper deals with the creation of an object-based land use and land cover classification of the most Southeast European megacity Istanbul, derivation of urban structure types based on this classification. WorldView satellite images with very high resolution have been used for this study. The results show that it is possible to differentiate between urban structure types simply based on a land use and land cover classification without additional data like cadastral or height information.
\end{abstract}

Keywords: LU/LC Classification, Urban Structure Types (UST), Remote Sensing, Istanbul.

\section{INTRODUCTION AND DEFINITION OF URBAN STRUCTURE TYPES}

The aim of this paper is to present an object-based classification - based on high-resolution WorldView-2 satellite image data - for the Megacity of Istanbul and to check whether urban structures can be captured using the data and presented methodology and to what extent it is possible to subdivide into different structure types at the building block level.

The concept of urban structure types (UST) was conceived in Germany in the 90s in order to be able to categorize the different urban settlement types. For efficient urban planning - in the form of traffic management, water and energy consumption, as well as waste management - the spatial distribution of the UST can play an important role. While there is no universally accepted definition of the term, UST are usually characterized by:

\section{LC/LU CLASSIFICATION AND \\ CLASSIFICATION OF URBAN STRUCTURE TYPES (UST)}

Many studies and scientific papers dealing with the classification of land cover and land use (LC/LU) in urban areas using Landsat TM data in connection
(1) geometry, density, as well as spatial nature of buildings;

(2) their use (housing, public, industry, etc.);

(3) as well as the properties of their environment (proportion and type of vegetation or water.

In addition to the external appearance and its use, urban structures are particularly notable for the spatial distribution of social classes. In this sense, a city can also be seen as a physical reflection of the population and their government who shaped it. Districts that were built in different time spans can differ significantly in terms of building density and existing structures. Furthermore, urban structures are scale-dependent and can be regarded as temporary, since the elements by which they define themselves undergo a constant transformation [1].

with pixel-based approaches. After launching Ikonos (1999) and Quickbird-2 satellites (2001) with a much higher resolution, the expansion or 
urban sprawl of a city could be examined in greater detail and it was possible to carry out more precise analyses of urban space. In 2008, with the commissioning of the GeoEye-1 satellite, the spatial resolution was less than 0.5 meters for the first time, but the spectral resolution remained unchanged. With WorldView-2 (Start 2009), eight multispectral channels - instead of the usual four standard channels - were made available for the first time, which means that the spectral properties of urban objects can be examined to a whole new extent [2]. Its successor, WorldView-3, was launched in 2014 and offers further new possibilities and significant advantages with regard to the classification of urban spaces. Because it not only has an even higher resolution, but also eight additional channels in the short-wave infrared range (SWIR) and 12 so-called CAVIS channels (Clouds, Aerosols, Water Vapor, Ice and Snow) [3].

[4] describes a method based on GLC (gray-level co-occurrence) matrices, which are calculated for each pixel in order to subsequently derive texture features. With the help of the resulting image of characteristics, the settlement areas can be very well demarcated from the other image structures. In general, numerous authors use texture features to improve classification accuracy [5]. [6], on the other hand, are concerned with performing an object-oriented classification for a city in Hungary using WV-2 data in order to test its potential for land cover classifications in urban areas. They focus primarily on the four additional channels that WV-2 offers and thus generate different normalized difference indices. They achieve an overall accuracy of $79.4 \%$. [7] also examine the potential of a WV-2 scene in terms of its high spatial and spectral resolution for a city in India. A number of vegetation classes and surface materials could be recorded, with an overall accuracy of $90.93 \%$. [8], however, could not improve the results using the four additional channels.

Many papers [9], [10]. [11], [12] deal with the comparison between pixel and object-based classification methods in urban space - for both high and medium-resolution data - or check the potential of the data for an object-based approach [13], [14], [15]. The use of a pixel-based method is often ruled out from the outset, since urban areas are characterized by a very large spectral heterogeneity, which has limits to the pixel-based methods. If the methods were compared, objectbased approaches for data with higher resolution provide the best results.

Classification of Urban Structure Types (UST): The work of [16] is to be examined in more detail here, because it provides very good comparability due to the same study area and similar data bases. Because in his work he uses both very highresolution data (IKONOS and Quickbird) and data with medium resolution (Landsat). His methodology includes an object-based approach, whereby the resulting land cover classification is then used in conjunction with a DTM to directly and indirectly derive factors that can be used to characterize urban landscapes. This includes, among other things, a building density analysis, the determination of the building height and different roof types. Furthermore, house types are differentiated based on their size and shape, and land use is subdivided. Other factors that are derived using the high-resolution and mediumresolution data are a large-scale sealing rate and indirectly a population density distribution. Another option is to determine parameters for the geographical location, such as an open space analysis or accessibility to traffic infrastructure.

[17] use Quickbird images to represent the structure of urban land use using an object-based classification for Santiago de Chile. The proportion of green spaces and undeveloped land at block level is used to separate the individual UST. The different types of residential buildings were also classified based on the roof materials. Texture information provided no positive results in this work and was therefore neglected. The overall accuracy of the classification is $81 \%$. [18] conduct a similar study for Leipzig, but using CIR aerial photographs. Furthermore, some thematic information from ATKIS was used to enable a more specific division of the UST. Here, an overall accuracy between $81 \%$ and $85 \%$ is achieved for two different recordings and 15 UST. In order to generate building blocks as reference units, vector data from the blocks themselves are often used [19], [20] or road networks are integrated into the segmentation process [21], [22]. Other authors who have dealt with the analysis of urban spaces using building block boundaries are [23], [24], [25].

[26] classify UST using high-resolution SAR images and examine the potential of $\mathrm{HOG}$ (Histogram of Oriented Gradients) features. These image descriptors are calculated for each block and the UST are then classified using a nearest neighbor classifier. Previously, all artificially created structures were extracted and further attributes, for example with regard to their geometry, were calculated, which were used for the classification. With this method an overall accuracy of $76 \%$ could be achieved. Furthermore, they deal with the problem that arises when several classes occur within a block. Several authors have included the building height - for example using LIDAR data as an additional property in order to improve the 
classification of urban structures. [20] for example, classified homogeneous urban areas by using the size, shape and height of buildings in connection with the density and ratio of certain previously created land cover classes. Other studies compare the resulting UST to socio-economic data at the block level. [27] was able to establish a connection to the selected educational courses of the residents in Santiago de Chile.

In the work of [28], a Support Vector Machine (SVM) is used to generate the previously defined urban structure classes using multiple data sources (3D model from Munich, Landsat TM 8 and Open Street Map data (OSM)) classify. 11 UST classes were defined. The overall accuracy is $70 \%$ and is therefore not particularly high in relation. A classification of UST by [19] with hyperspectral images and elevation information were used. The aim of this work is to demonstrate the potential of hyperspectral data in relation to the determination of surface materials and subsequently the characterization of UST. 38 surface materials were identified in this way and the average absolute error

\section{METHODOLOGY}

For the WorldView-2 scene, which was made available for this work, a pan-sharpening has already been carried out. This is a technique in which the high-resolution panchromatic image (in this case $0.5 \mathrm{~m}$ ) and the medium-resolution multispectral image $(2 \mathrm{~m})$ are combined to obtain a multispectral image with a higher resolution. This is a function in Erdas IMAGINE that was specially developed for WorldView 2 data, but can also be used for other satellite image data. The result with which the classification was subsequently carried out has a spatial resolution of 0.5 meters.

The creation of the object-based classes for the LU/LC classification is an important step in the process of a classification. The derivable classes depend primarily on the data material used to carry out the classification. In general, a distinction must be made between land use and land cover classes. The land cover describes the physical surface, i.e. the material with which the land is covered and can be determined by analyzing satellite or aerial data. Land use, however, describes the form in which the land is used by humans. For this reason, the latter requires a certain amount of expert knowledge of the study area, which makes it more difficult to create land use classes [32].

Figure 1 illustrates the process of classifying land is less than $8 \%$. Furthermore, 7 spatial indicators for the description of the urban land cover were derived, the error here being between $3 \%$ and $11 \%$. [29] has set itself the goal of using an object-based classification for the Greater Cairo metropolitan region to distinguish the formal from the informal settlements and to further subdivide the informal settlements into different types. Here too, very positive results are achieved with around $86 \%$ for various subsets. [30] also deal with the detection of urban structures within informal settlements in Salvador, Brazil. An object-based classification is also carried out here, using aerial photographs. Another example of a successful object-based classification of complex urban structures (including informal settlements) using IKONOS data is [31]. These examples clearly show that there is no precise definition of UST. They can be understood as a single unit (e.g. a single-family home) as well as summarized in a neighbor context and in connection with many different areas of application, even if the term UST is not clearly mentioned.

cover and land use classes based on two different levels. All those segments that could not be assigned to a class due to properties that are too different or too little pronounced are assigned to the class to which they are most similar at the end. The position of the classified segments in relation to objects already classified is also considered.

Differentiation of settlement structures: Istanbul can be divided into 7 classes in terms of urban structure types [34]:

- The densely populated areas of the old town (partially redesigned through new construction)

- Multi-storey apartment buildings (apartment buildings, multi-storey buildings)

- Peripheral multi-storey apartment blocks, which represent a further development of the apartment house construction, settlement satellites

- Irregular settlements (Gececondular), the majority of which were redesigned and replaced by multi-party housing

- Detached houses and residential complexes, open buildings on the outskirts

- Scattered residential areas (along the Bosphorus or on the Marmara coast)

- Other structures such as industrial areas. 


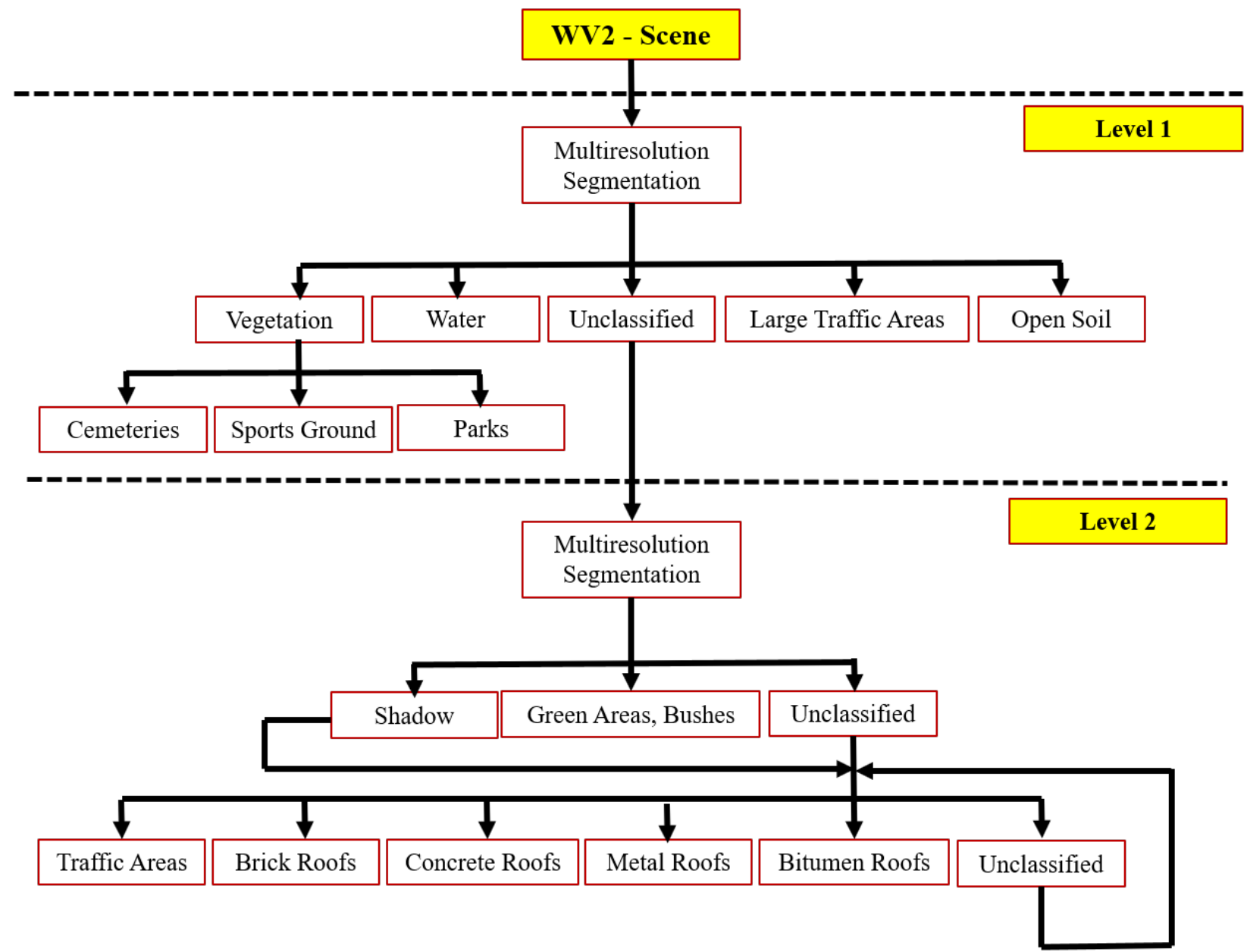

Figure 1. Classification tree for the WV-2 scene (LC/LU) (source [33].

Since the detached houses and the settlement tend to be located on the outskirts of the city, both classes are not included in the WV2 scene, just like the class of the residential areas. In order to avoid possible misinterpretations, an attempt was made to classify the urban structures in this work purely from a physiognomic point of view.

Since it is difficult to infer urban structures from individual image objects, structural blocks are mostly created in urban areas in order to be able to view individual objects in connection with their surroundings. For the subsequent differentiation of the different settlement structures, the previously classified streets are used as a thematic layer and a new segmentation is carried out on the basis of this layer. A building block level is thus created, in which case only blocks that also contain buildings are relevant.Figure 2 shows an example on the left for which the automated creation of the blocks worked well. On the right in the image you can see a section of the large industrial areas west of the wall. Too many individual buildings were recorded here as separate blocks, which is why they had to be combined into larger blocks. The large vegetation and water areas and the open soil class are reloaded into the block level. In this case, individual buildings surrounded by large areas of vegetation are added to the same classes. The basic level for differentiation at the building block level is the classification of LC / LU.

Another level is created between the base level and the block level, into which all buildings are taken from the base level. Then all those buildings are extracted that do not exceed a certain size and above all do not adjoin other buildings. This creates the class of stand-alone buildings. This contrasts with the class of building complexes. The class of standalone buildings will later be used to classify blocks with open structures.. The characteristics of the individual classes, which are used for differentiation and implemented as rules, result on the one hand from the closer examination of the study area and secondly from a visual observation of the scene. These are summarized again below and the individual classes are described in more detail. 

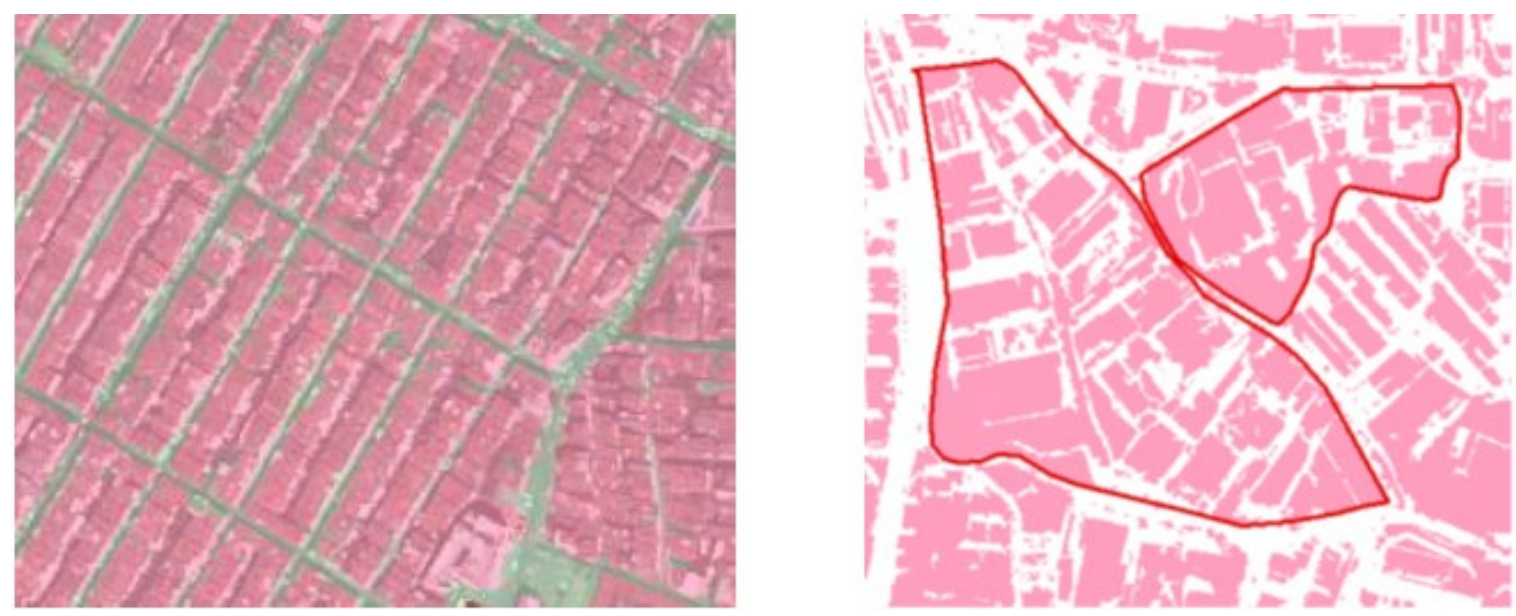

Figure 2. Comparison of segmented Built-Up Blocks (source: [33], adopted).

Table 1. Parameter used to define Urban Structure Types (UST)

\begin{tabular}{|c|c|c|c|c|c|}
\hline & 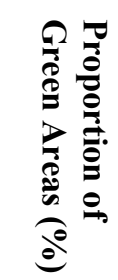 & 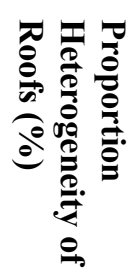 & 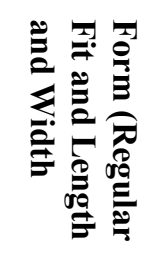 & 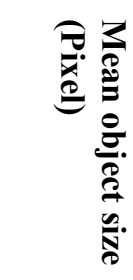 & 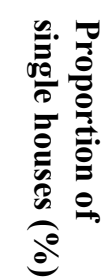 \\
\hline Old Town & $0-15$ & $>30$ & $\mathrm{RF}<0.7$ & $<350$ & - \\
\hline Block-like Built-Up Areas & $10-30$ & - & $\mathrm{RF}>0.7$ & - & -- \\
\hline Closed, Irregular Built-Up Areas & $0-15$ & - & $\begin{array}{l}\mathrm{RF}>0.8 \\
\mathrm{~L} / \mathrm{W}>3\end{array}$ & - & - \\
\hline Closed, Regular Built-Up Areas & $10-25$ & - & $\mathrm{RF}<0.7$ & - & - \\
\hline Open, Dense Built-Up Areas & $30-50$ & - & - & - & $>25$ \\
\hline Open, Loose Built-Up Areas & $>50$ & - & - & - & $>20$ \\
\hline Industrial Areas & $0-10$ & $>40$ & - & $400-800$ & - \\
\hline
\end{tabular}

Table 1 summarizes the parameters that were used for the classification of the individual urban structure types (UST). The proportion of the respective parameter is always calculated on the entire block in the super level.It therefore makes sense that the proportion of free-standing buildings for the open, loose building class is lower than for the open, tight building class. Because even if in the former all buildings should in principle be standalone and these could also be recorded much more easily than such, the proportion of green space for this class is at the same time significantly higher,

\section{RESULTS AND ACCURACY ANALYSIS}

Figure 3 shows the LU/LC classification result and Figure 4 the classification results of the urban structure types (UST) for the WorldView 2 scene. The accuracy of a classification describes the degree of correspondence between the classified objects and the objects in reality. This is necessary i.e. each block generally has very few buildings. The parameters used were chosen in order to avoid misclassifications as far as possible. For those blocks that were not yet classified, the selected threshold values were adjusted or neighborhood relationships included, or the blocks were assigned to the "other class".

The latter is not listed in the table, because on the one hand there are 'leftover' blocks and on the other hand the parameters of the blocks classified as such vary too much or have been individually adapted for some blocks (e.g. Grand Bazar).

in order to be able to objectively determine the reliability of the classification result. A popular method for determining the accuracy of the classification is to create an accuracy analysis in the form of an error matrix or confusion matrix. 


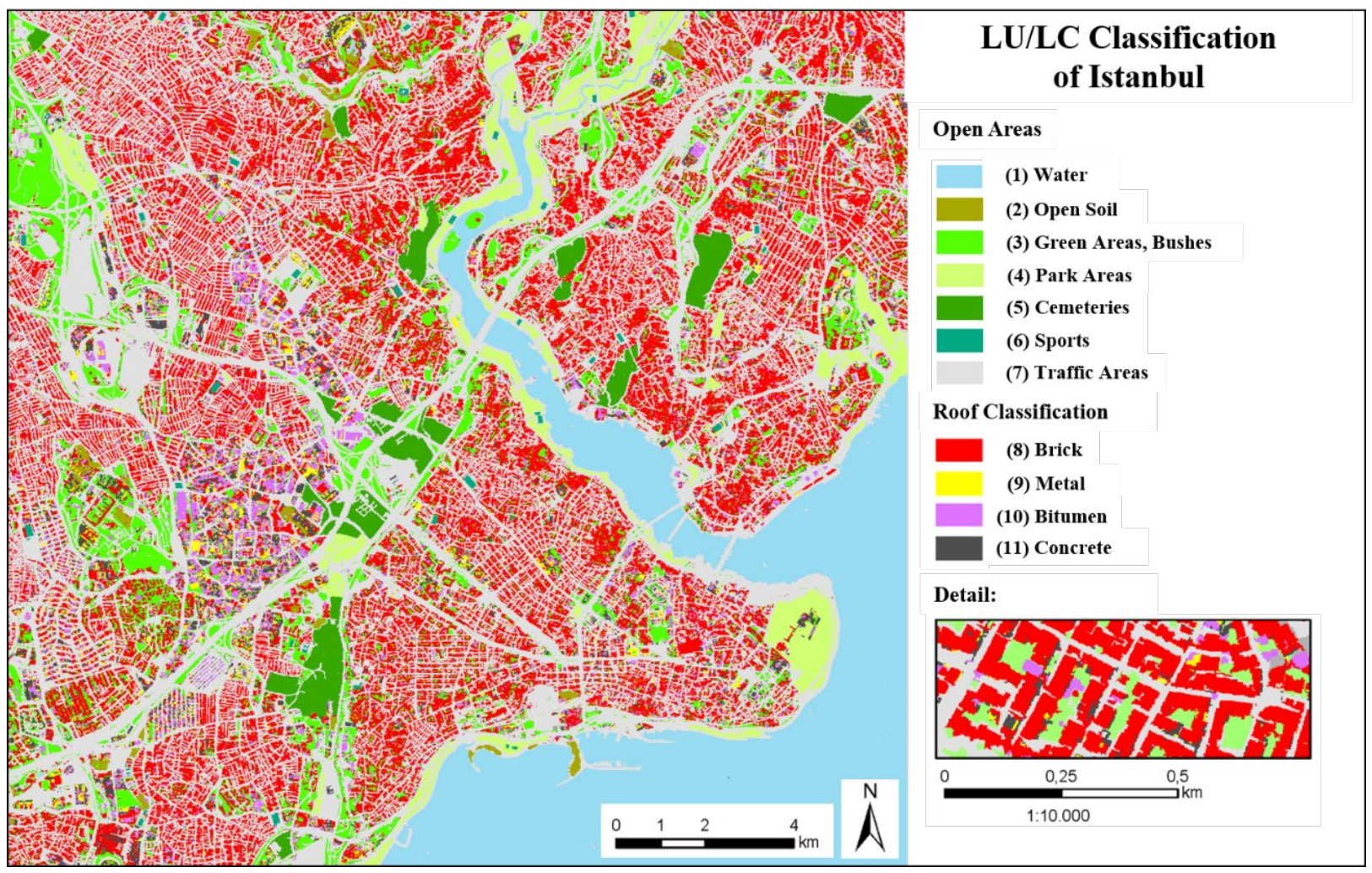

Figure3. LU/LC Classification of Istanbul (source: [33], adopted).

In this case, 100 objects per class are selected using a random algorithm and checked for their correct allocation to a class. If the object was classified incorrectly, the matrix records which class it was incorrectly assigned to. Finally, the producer and user accuracy can be calculated from this. The former indicates the probability that the object was correctly classified in reality, i.e. the underestimation of objects is described. It is calculated using the quotient of the correctly classified objects and the total objects that fall into this class. User accuracy describes the likelihood that the classified object and the object will match in reality. It therefore indicates the over-estimation of objects, i.e. when more objects have been classified than occur in reality. It results from the number of correctly classified objects and the reference objects. The overall accuracy of the classification, also referred to as overall accuracy, can also be calculated at this point. It indicates the ratio between the total number of all objects in the error matrix and the correctly classified objects of all classes [35].

Table 2. Confusion Matrix of LU/LC Classification of the WV2-Scene (Legend see Figure 3, [33]).

\begin{tabular}{|c|c|c|c|c|c|c|c|c|c|c|c|c|c|}
\hline & $\mathbf{( 1 )}$ & $\mathbf{( 2 )}$ & $\mathbf{( 3 )}$ & $\mathbf{( 4 )}$ & $\mathbf{( 5 )}$ & $\mathbf{( 6 )}$ & $\mathbf{( 7 )}$ & $\mathbf{( 8 )}$ & $\mathbf{( 9 )}$ & $\mathbf{( 1 0}$ & $\mathbf{( 1 1 )}$ & $\begin{array}{c}\text { Tota } \\
\text { I }\end{array}$ & $\begin{array}{c}\text { Producer' } \\
\text { s Accuracy } \\
\text { in \% }\end{array}$ \\
\hline $\mathbf{( 1 )}$ & 100 & 0 & 0 & 0 & 0 & 0 & 0 & 0 & 0 & 0 & 0 & 100 & 100.0 \\
\hline $\mathbf{( 2 )}$ & 0 & 87 & 1 & 0 & 0 & 3 & 1 & 7 & 0 & 1 & 2 & 102 & 85.3 \\
\hline$(\mathbf{3})$ & 0 & 3 & 92 & 7 & 4 & 3 & 0 & 2 & 0 & 1 & 0 & 112 & 82.1 \\
\hline $\mathbf{4})$ & 0 & 0 & 3 & 93 & 0 & 0 & 0 & 0 & 0 & 0 & 0 & 96 & 96.9 \\
\hline $\mathbf{( 5 )}$ & 0 & 0 & 2 & 0 & 96 & 0 & 0 & 0 & 0 & 0 & 0 & 98 & 98.0 \\
\hline$(\mathbf{6})$ & 0 & 0 & 1 & 0 & 0 & 90 & 0 & 0 & 0 & 0 & 0 & 91 & 98.9 \\
\hline$(\mathbf{7})$ & 0 & 1 & 1 & 0 & 0 & 2 & 81 & 5 & 8 & 7 & 9 & 114 & 71.1 \\
\hline$(\mathbf{8})$ & 0 & 8 & 0 & 0 & 0 & 1 & 0 & 82 & 0 & 4 & 0 & 98 & 83.7 \\
\hline$(\mathbf{9})$ & 0 & 0 & 0 & 0 & 0 & 0 & 3 & 1 & 81 & 1 & 11 & 99 & 81.8 \\
\hline$(\mathbf{1 0})$ & 0 & 0 & 0 & 0 & 0 & 0 & 5 & 1 & 2 & 75 & 0 & 81 & 92.6 \\
\hline $\mathbf{( 1 1 )}$ & 0 & 1 & 0 & 0 & 0 & 1 & 3 & 2 & 9 & 11 & 78 & 109 & 71.6 \\
\hline Total & 100 & 100 & 100 & 100 & 100 & 100 & 100 & 100 & 100 & 100 & 100 & & \\
\hline $\begin{array}{c}\text { User's } \\
\text { Accurac } \\
\text { y in \% }\end{array}$ & 100.0 & 87.0 & 92.0 & 93.0 & 96.0 & 90.0 & 81 & 82.0 & 81.0 & 75.0 & 78.0 & & $\mathbf{8 6 . 8}$ \\
\hline
\end{tabular}




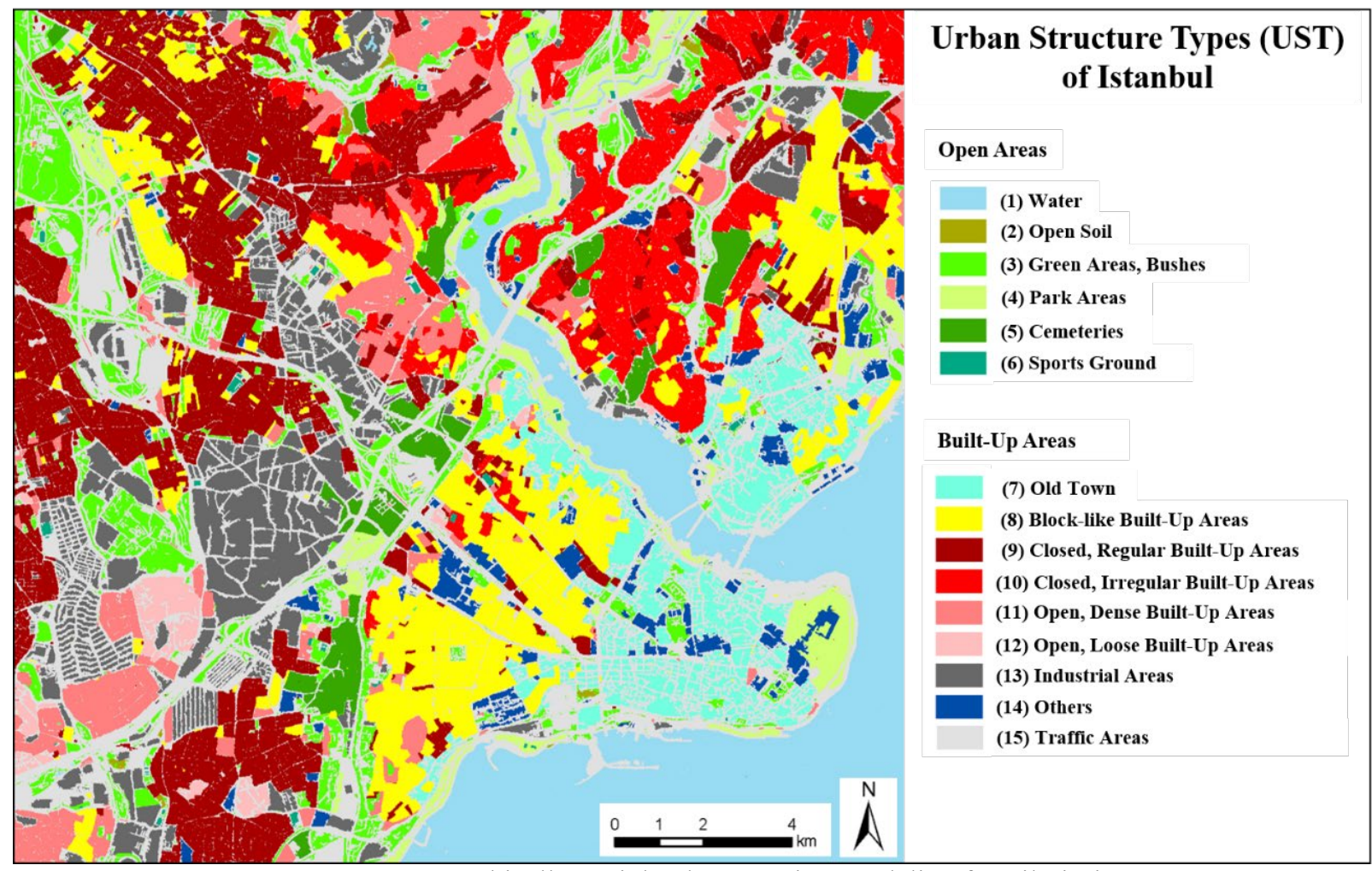

Figure 4. Geographically Weighted Regression Modeling for Filariasis.

Urban Structure Types (UST) Classification of Istanbul (source: [33], adopted).

The overall accuracy for the LU / LC classification of the WV2 scene is $86.8 \%$ (see Table 2) and is therefore extremely satisfactory, especially with regard to the high number of classes. The classification of the individual roof materials turned out to be the most difficult, because they often have spectral properties that are too similar to be able to differentiate them correctly. For example, many of the bitumen roofs were recorded as concrete roofs and concrete roofs as metal roofs, which results in the relatively low user accuracy of $75 \%$ for the bitumen roof material and $78 \%$ for concrete. In terms of producer accuracy, the category of traffic areas is the worst with a value of $71.1 \%$, which means that many roads have not been recognized as such and have therefore been assigned to a different class. This in turn meant that some of the blocks derived from it had to be processed manually to separate them. The remaining classes, especially water and the individual vegetation areas, have very high levels of accuracy, both user and producer accuracy.

Table 3. Confusion Matrix of Urban Structure Types (UST)

Classification of the WV2-Scene (Legend see Figure 3, [33]).

\begin{tabular}{|c|c|c|c|c|c|c|c|c|c|c|}
\hline & $\mathbf{( 7 )}$ & $\mathbf{( 8 )}$ & $\mathbf{( 9 )}$ & $\mathbf{( 1 0 )}$ & $\mathbf{( 1 1 )}$ & $\mathbf{( 1 2 )}$ & $\mathbf{( 1 3 )}$ & $\mathbf{( 1 4 )}$ & Total & $\begin{array}{c}\text { Producer } \\
\text { Accuracy } \\
\text { (\%) }\end{array}$ \\
\hline $\mathbf{( 7 )}$ & 82 & 4 & 1 & 0 & 0 & 0 & 0 & 1 & 87 & 94.3 \\
\hline$(\mathbf{8})$ & 2 & 78 & 0 & 4 & 5 & 2 & 0 & 1 & 97 & 83.0 \\
\hline$(\mathbf{9})$ & 4 & 9 & 92 & 6 & 4 & 0 & 1 & 1 & 117 & 78.6 \\
\hline $\mathbf{( 1 0 )}$ & 6 & 4 & 6 & 84 & 6 & 0 & 0 & 0 & 103 & 80.0 \\
\hline$(\mathbf{1 1})$ & 3 & 5 & 0 & 5 & 82 & 5 & 2 & 1 & 104 & 80.4 \\
\hline $\mathbf{( 1 2 )}$ & 0 & 0 & 0 & 0 & 1 & 86 & 0 & 3 & 90 & 95.6 \\
\hline $\mathbf{( 1 3 )}$ & 0 & 0 & 1 & 0 & 0 & 0 & 93 & 4 & 99 & 94.9 \\
\hline $\mathbf{( 1 4 )}$ & 1 & 0 & 0 & 1 & 2 & 7 & 4 & 89 & 103 & 85.6 \\
\hline Total & 100 & 100 & 100 & 100 & 100 & 100 & 100 & 100 & & \\
\hline $\begin{array}{c}\text { User's } \\
\text { Accuracy } \\
\text { in \% }\end{array}$ & 82.0 & 78.0 & 92.0 & 84.0 & 84.0 & 86.0 & 93.0 & 89.0 & & $\mathbf{8 5 . 8}$ \\
\hline
\end{tabular}

Table 3 shows the confusion matrix for the classification of the individual urban structure types (UST) of the WV-2 scene. The overall accuracy is
$85.8 \%$ and is therefore largely positive. Above all, the class of the industrial areas could be recorded very well, as well as the class of the closed regular 
cladding, which can be distinguished from the other classes very well due to its rectangular blocks and the extremely low proportion of green space. However, it is striking that at the same time some blocks of this type were incorrectly assigned to other classes, but especially to the block perimeter development. The user accuracy is above average at $92 \%$, the producer accuracy is at $78.6 \%$ for the class of closed, regular installation the lowest of the

\section{CONCLUSION}

The classification of urban structure types (UST) for the WV2 scene shows with a high overall accuracy of $85.8 \%$ that the chosen approach is suitable for the tasks. This consists of an objectbased classification of land cover and a subsequent derivation of certain indicators/parameters in order to be able to differentiate the structure types at the block level. One problem that can arise is the occurrence of several classes per block. However, this problem could not be dealt with in more detail in this work, as this would have turned out to be too complex. In order to derive the indicators for differentiating the structures, the detection of smallscale, heterogeneous objects in urban areas is essential.

Especially for rapidly growing megacities, it is often difficult to keep an overview of the constantly changing dynamics of the city. The traditional visual mapping of such large areas is an extremely time and cost intensive procedure. Remote sensing can help here and play a supporting role, because current and large-scale data can be of enormous importance for the future spatial development of a city. The subdivision into different structure types, as in this work, can provide essential insights into the structure of a city and thus relevant information for urban planning. For example, conclusions can be drawn about socio-economic parameters such as population density, and in turn statements can be made about the vulnerability of a city. The quantification of the individual structure types can entire classification. The classification of the block building class was probably the most difficult in this context. Because the rectangular shape and a certain proportion of green space were often not enough properties to correctly classify blocks of this type, which is characterized above all by the arrangement of the buildings around an inner courtyard.

also be relevant here and provides an additional overview of the spatial structure of a city in addition to the visual one. Given the availability of the data, a socio-economic analysis would be a conceivable option for the reuse of the data sets created in this work.

Several parameters can be derived purely from the satellite image data (WV2), which can then be used for the classification of the UST. In addition to the roofing materials, this also means determining the type of roof (flat or gable roof). However, the latter achieved results that were too imprecise for this work, which is why this factor was not included in the classification of urban structures. Other parameters are the proportion of green areas and the degree of sealing, if you consider the roof and traffic areas together. The size and shape of the objects, both on the building and on the block level, can also serve as indicators to differentiate structure types. In addition, the environment of the individual objects can be integrated indirectly as parameters. The present work shows that object-based classification of UST is possible without additional information such as the building height. The latter would definitely increase the quality of the classification or allow an additional differentiation of the structures, but is always associated with additional costs. In this specific case, the quality of the land cover classification is all the more crucial, since the UST is derived from it and any misclassifications can propagate.

\section{REFERENCES}

[1] Taubenböck, H., Esch, T., Wurm, M., Thiel, M., Ullmann, T., Roth, A., Schmidt, M., Mehl, H., Dech, S., 2008: Urban structure analysis of mega city Mexico City using multi-sensoral remote sensing data. In: The International Society for Optical Engineering 7110, p. 1-12.

[2] Ribeiro, B.M.G., Fonseca, L.M.G., 2013. Urban Land Cover Classification using WorldView-2 Images and C4.5 Algorithm. In: Joint Urban Remote Sensing Event (JURSE).

[3] Digital Globe (Ed.), 2013. WorldView-2 DataSheet, https://www.spaceimagingme.com/downloads/sensors/datasheets/WorldView2

[4] Steinnocher, K., 2003. Landbedeckung im Stadt- und Stadtumland. Workshop „Geodaten zur Landbedeckung in Österreich“ "http://ivfl.boku.ac.at/workshop/pdf/GEOLC2003_6.pdf

[5] Radberger, R., 2001. Monitoring der Verstädterung im Großraum Istanbul mit den Methoden der Fernerkundung und der Versuch einer räumlich-statistischen Modellierung. Dissertation. Georg-August-Universität Göttingen. 
Fakultät für Forstwissenschaften und Waldökologie, Göttingen.

[6] Zhoua, X., Jancsób, T., Chena, C., Veroneb, M.W., 2012. Urban Land Cover Mapping Based on Object Oriented Classification Using WorldView 2 Satellite Remote Sensing Images. In: International Scientific Conference on Sustainable Development \& Ecological Footprint, Hungary.

[7] Kumar, M., Roy, P., 2013. Utilizing the Potential of World View -2 for Discriminating Urban and Vegetation Features Using Object Based Classification Techniques. In: Journal of the Indian Society of Remot Sensing. Indian Institue of Remote Sensing 41, 3, p. 711-717.

[8] Aguilar, M.A., Saldaña, M.M., Aguilar, F.J., 2013. GeoEye-1 and WorldView-2 pansharpened imagery for objectbased classification in urban environments. In: International Journal of Remote Sensing 34, 7, p.2583-2606.

[9] Wu, Y, Ke, Y., Gong, H., Chen, B, Zhu, L., 2014. Comparison of object-based and pixelbased methods for urban land-use classification from WorldView-2 imagery. In: Third International Workshop on Earth Observation and Remote Sensing Applications (EORSA).

[10] Shackelford, A.K., Davis, C.H., 2003. A Combined Fuzzy Pixel-Based and Object-Based Approach for Classification of High-Resolution Multispectral Data Over Urban Areas. In: IEEE Transactions on Geoscience and Remote Sensing 41, 10, p. 2354-2363.

[11] Myint, S.W., Gober, P., Brazel, A., Grossman-Clarke, S., Weng, Q., 2011. Per-pixel vs. object-based classification of urban land cover extraction using high spatial resolution imagery. In: Remote Sensing of Environment 115, 5, p. 1145-1161.

[12] Darwish, A., Leukert, K., Reinhardt, W. (2003): Urban Land-Cover Classification: An Object Based Perspective. In: 2nd GRSSLSPRS Joint Workshop on Remote Sensing and Data Fusion over Urban Areas, p.278-282

[13] Mott, C., 2005. Objektorientierte Klassifikationsstrategien zur Erfassung der Landnutzung aus hochauflösenden Fernerkundungsdaten. Dissertation. TU München. Department für Ökosystem- und Landschaftsmanagement Lehrstuhl für Landnutzungsplanung und Naturschutz, 141p.

[14] Rizvi, I.A., Mohan, B.K., 2012. Object Based Analysis of Worldview-2 Imagery of Urban Areas. In: IEEE International Geoscience and Remote Sensing Symposium (IGARSS).

[15] Niebergall, S., Loew, A., Mauser, W., 2007. Object-Oriented Analysis of Very High Resolution QuickBird Data for Mega City Research in Delhi/India. In: Urban Remote Sensing Joint Event.

[16] Taubenböck, H., 2007. Vulnerabilitätsabschätzung der erdbebengefährdeten Megacity Istanbul mit Methoden der Fernerkundung. Dissertation. Bayerischen Julius-Maximilian-Universität Würzburg.

[17] Huck, A., Hese, S., Banzhaf, E., 2011. Delineating parameters for object-based urban structure mapping in Santiago de Chile using Quickbird data. In: International Archives of the Photogrammetry, Remote Sensing and Spatial Information Sciences - ISPRS Archives 38, p. 131-136.

[18] Banzhaf, E., Hofer, R., 2008. Monitoring Urban Structure Types as Spatial Indicators with CIR Aerial Photographs for a More Effective Urban Environmental Management. In: IEEE J. Sel. Top. Appl. Earth Observations Remote Sensing 1, 2, p. 129-138.

[19] Heldens, W., 2010. Use of airborne hyperspectral data and height information to support urban microclimate characterisation. Dissertation. Bayerische Julius-Maximilians-Universität Würzburg.

[20] Wurm, M., Taubenböck, H., Roth, A., Dech, S., 2009. Urban structuring using multisensoral remote sensing data. By the example of the German cities Cologne and Dresden. In: Joint Urban Remote Sensing Event (JURSE).

[21] Beykaei, S.A., Zhong, M., Shiravi, S., Zhang, Y., 2013. Development of an Automatic Land Use Extraction System in Urban Areas using VHR Aerial Imagery and GIS Vector Data. In: International Journal of Transportation Engineering 1, 2, p. 69-79.

[22] Louw, J., 2011. Context based detection of urban land use zones. Master Thesis. University of Cape Town.

[23] Bauer, T., Steinocher, K., 2001. Per-parcel land use classification in urban areas applying a rule-based technique. In: GeoBIT/GIS 6, p. 24-27.

[24] Hermosilla, T., Palomar-Vázquez, J., Balaguer-Beser, A., Balsa-Barreiro, J., Ruiz, L.A., 2014. Using street-based metrics to characterize urban typologies. In: Computers, Environment and Urban Systems 44, p. 68-79.

[25] Yoshida, H., Omae, M., 2005. An approach for analysis morpholgy: Methods to derive morphological properties of city block by using an urban landscape model and their interpretations. In: Computers, Environment and Urban Systems 29, 2, p. 223-247. 
[26] Novack, T., Stilla, U., 2014. Classification of Urban Settlements Types based on spaceborne SAR datasets. In: ISPRS Ann. Photogramm. Remote Sens. Spatial Inf. Sci. II-7, p.55-60.

[27] Krellenberg, K., Höfer, R. \& Welz, J., 2011. Relaciones y dinámicas recientes entre el uso de suelo y la composición socioeconómica en Santiago de Chile: el caso de la comuna de Peñalolén. In: Revista de Geografía Norte Grande 48, p. 107-131.

[28] Poncet-Montanges, A., 2014. Classification of urban structural types (UST) using multiple data sources and spatial priors. Master Project. Ecole Polytechnique Federale de Lausanne.

[29] Majhen, P., 2016. Objektbasierte Klassifikation und physischer Strukturvergleich der informellen Siedlungstypen in der Metropolregion Greater Cairo. Master Thesis. NAWI GRAZ.

[30] Brito P L., Arenas H., Lam N. \& Quintanilha J A., 2008. Recognition of urban patters related to Leptospirosis contamination risks using object based classification using aerial photography. Test areas: informal settlements of the railroad suburb of Salvador, Brazil. In: IEEE International Geoscience and Remote Sensing Symposium (IGARSS).

[31] Hofmann, P., 2001. Detecting Informal Settlements from IKONOS Image Data Using Methods Of Object Oriented Image Analysis - An Example from Cape Town (South Africa). In: Proceedings of the 2nd international symposium remote sensing of urban areas, Regensburg, Germany, June 22-23, 2001, p. 107-118.

[32] Manakos, I., Braun, M., 2014. Land use and land cover mapping in Europe: practices and trends. Springer Verlag, $441 \mathrm{p}$.

[33] Mitterhuber, L., 2018. Objektbasierte Klassifikation urbaner Strukturen der Megacity Istanbul. Masterthesis. University of Graz.

[34] Seger, M., Palencsar, F., 2006. Istanbul - Metropole zwischen den Kontinenten, Berlin. Stuttgart: Gebrüder Borntraeger Verlagsbuchhandlung, $277 \mathrm{p}$.

[35] Kleinschmit, B., Bahls, A., 2012. KLIWAS. Querschnittsaufgabe Fernerkundung Konzeption für ein Langzeitmonitoring der gezeitenbeeinflussten Vegetation mit hochauflösenden Satellitendaten. Koblenz: Bfg Verlag, $86 \mathrm{p}$. 